\title{
South African Career Development Institution Management in Graduates Alumni Assisten
}

\author{
Tonto Chioma Dominic ${ }^{1}$, Iyabo Ike Sobowale ${ }^{1}$ \\ ${ }^{1}$ Department of Educational Management, Faculty of Education, Ignatius Ajuru University of \\ Education, Nigeria
}

\begin{abstract}
This article discusses career development management that can help career empowerers combine skills such as applying theoretical constructs realistically and creatively to focus on innovative ways of doing things that make careers possible as factors that provide support to employees in the workplace and contribute on their professional development. In contrast to other approaches to career development, the conventional approach to career development is mainly focused with techniques that are meant to utilize skill development and supply to drive economic growth rather than anything else. However, although the promotion of economic growth is an important goal for career development in South Africa, it is not the only goal for the country's development agenda, which includes a number of other goals. Globally, a vision of career development based on clearly defined economic goals would be at conflict with South Africa's development rhetoric, according to the World Bank's Africa Development Report.
\end{abstract}

Keywords: Career Development, Graduates Alumni, Management

Received: May 12, 2021

Revised: June 25, 2021

Accepted: July 5, 2021

\section{Introduction}

Individuals who possess this ability are more likely to have a successful professional path. Generally speaking, career enhancers are abilities that allow people to be more successful in their professional lives. Skills such as applying theoretical constructs realistically and creatively to focus on innovative ways of doing things that make careers possible as well as factors that support employees in the workplace and contribute to their professional development are all combined to create career empowerment. The latter definition was used for the purposes of this research, and it serves as the foundation for the development of the higher education career-enabler framework.

A career-enabler framework is clearly necessary as a result of this; businesses must grasp the elements that will contribute to the professional development of their workers in order to be successful. Career empowerment is linked with two constructs: practical/creative talents on the one hand, and self-and-other skills on the other (Coetzee Schreuder, 2009; Di Fabio \& Maree, 2013). Applying current theoretical frameworks to new methods of doing things is an example of practical/creative talents in action. Individuals with high levels of interpersonal intelligence (the ability to understand, respect, empathize, and interact effectively with others) and intrapersonal intelligence (the ability to understand one's feelings and motivations while exercising self-discipline in one's interactions) are considered to have high levels of selfintelligence and other skills.

Orientation toward a professional career Career anchors are patterns of self-perceived skills and abilities that affect one's decision-making in relation to one's professional life. To express the fact that one's professional self-concept is built on eight categories or anchors, such as: The following characteristics are required: (1) autonomy/independence (the desire to be free of 
organizational constraints in order to pursue professional competency); (2) technical/functional competence (the desire to acquire technical or functional knowledge and expert expertise); (3) general managerial competence (desire to achieve managerial level of interpersonal, political, analytical and financial skills) (4) entrepreneurship/creativity (the desire to create or build something); (5) lifestyle (the desire to integrate work, family, and self-care into a coherent lifestyle); (6) pure challenge (the desire to test one's abilities); (7) service/dedication to a cause (the desire to align work activities with personal skills and values associated with helping the community); and (8) security/stability (the desire to have job security (see also). Groups that assist with one's professional development Individuals who make decisions about their personal, familial, and professional growth may become more conscious of the values and motivations that shape the decisions they make as a result of their decisions (Duffy \& Dik, 2009; Taskforce et al., 2013).

Knowing one's professional orientation is very significant since it has an impact on one's job choice as well as on the development of one's life goals and aspirations. Several types of professional support groups have been discovered, including those for self-transcendence (using technical and specialized affirmations), self-improvement (using enlarged objectives), and self-preservation (through motive occupations and needs) Objectives of the research The purpose of this research is to offer a career-enabler framework that may be utilized in higher education institutions to structure career talks. Specifically, we want to investigate the three most significant career preferences for workers in higher education institutions, as well as to create a framework for career enablers that will assist institutions in having career dialogues with their employees. Aims of this research include determining the number and nature of career anchors that an individual from a higher education institution may have, determining the three most important career preferences for employees in a higher education institution, and developing an institution-wide career-activating framework to assist with career conversations.

\section{The Importance of Developing Career for Graduate Alumni}

Currently and in the future, the capacity of companies to recruit and retain knowledge employees will be critical to their success in the knowledge economy. When one considers that knowledge workers will overtake manual laborers as the main category of employees in the future, it seems that knowledge workers will have limitless upward career mobility, with the possibility for failure or success in their endeavors.

A particular need for knowledge workers is created by the expansion of specific sectors of the economy, along with the retirement of a large number of knowledge employees. Given this expansion, knowledge workers must get formal education before they may join the area of knowledge labor. Once knowledge workers have begun working in the industry, they will need to continue their education to ensure that their expertise stays up to date. In such a situation, the need of continual learning for knowledge workers is highlighted, since information becomes rapidly outdated in knowledge-based companies (Kefela, 2010; Maruta, 2012). 


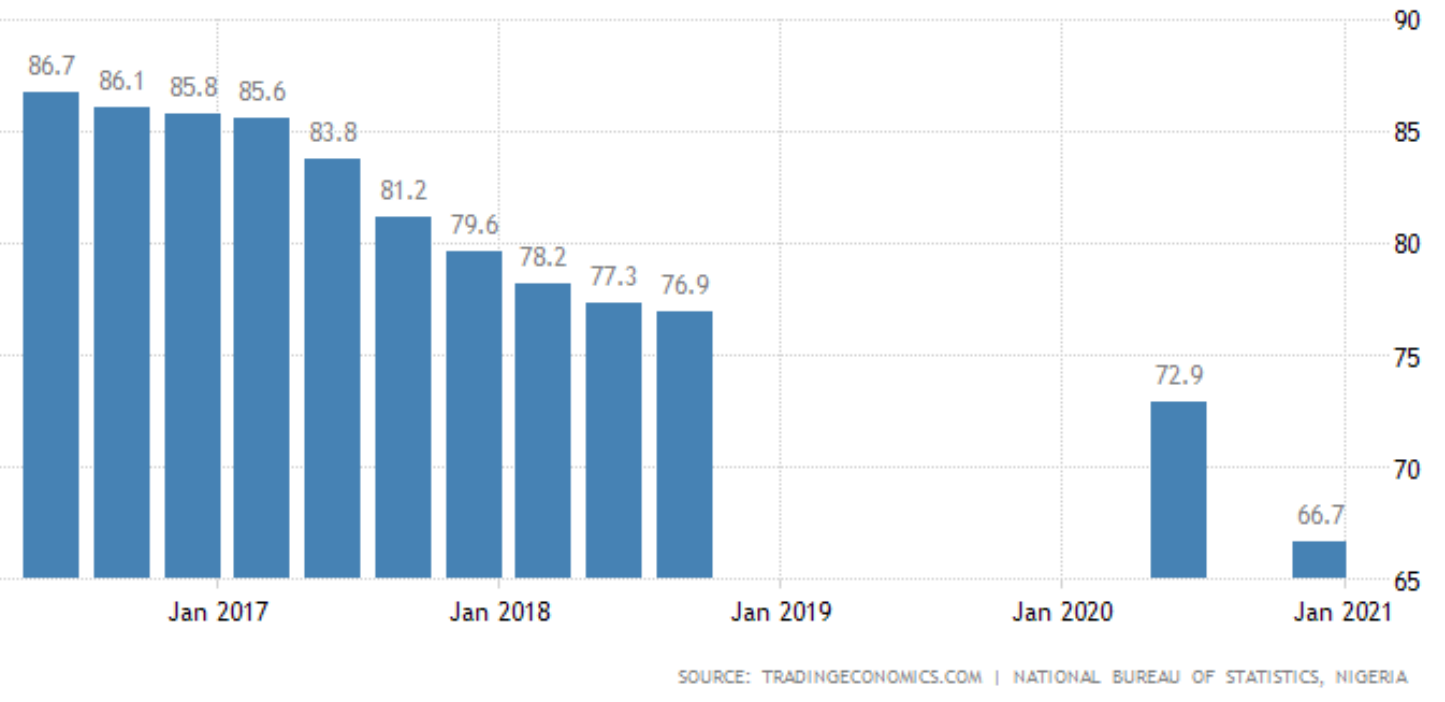

Figure 1. Decrease in Employability Rate in Nigeria

It is necessary to prepare for the transition of knowledge workers from their younger to older ages in order to guarantee that information is passed down across generations. The rise in the average length of service of employees has generated new challenges for businesses. Knowledge workers are no longer able to do the same job for fifty years in a row. A second job after retirement is seen as a means of maintaining one's mental health. It also benefits the company since knowledge employees may bring in new ideas and innovations as part of their job responsibilities as freelancers, contractors, or consultants, which helps the organization grow. In order to maintain important expertise in areas such as cost reduction and the development of new goods and services, companies must modify their knowledge management strategies (Hong et al., 2011; Chang \& Lin, 2015).

\section{Career as Life}

People spend a greater proportion of their time at work than at home; in other words, employment serves as a metaphor for a person's whole existence. When this happens, careers "become a significant role in deciding the overall quality of life." The fact that they have reached the end of their working lives causes many individuals to become very dissatisfied when they reach the age of retirement. Frequently, retirees go on to new positions and continue to work as consultants for the company from which they retired.

\section{Equality}

During one's professional life Individuals who have a successful profession are in a better position to attain social elevation and personal freedom in a variety of areas, ranging from equality to career pathways and organizational growth. Most South African automotive firms have adopted an affirmative action policy, which serves as an excellent illustration of how equality with peers in the same industry may be accomplished via career pathways for formerly disadvantaged workers. A number of DSGN are selected to important positions within the organization and undertake rigorous training in order to be on level with their colleagues. Women have also been attracted into professions, and they are now in the process of overcoming past inequities in the labor market, as well. Because job creation is a critical element in the present South African political landscape and has a significant effect on societal development, businesses are being compelled to devote greater resources to career management in order to solve this problem. 


\section{Career Mobility}

Generally speaking, job mobility refers to people moving around in order to improve their own professional careers. As a result of employment reservation based on race and gender in South Africa, the mobility of those who have been classified as such has been hindered. The Black Economy Empowerment Commission's job equity strategy was intended to fail because it failed to adequately address fundamental problems, such as a lack of career options for DSGN and a scarcity of skills, among other things. In addition to professional reasons, work mobility may be affected by personal variables. For example, workers nowadays are more conscious of their work location, quality of life, leisure, and family while choosing a job, or when they get a promotion or transfer.

\section{Knowledge Development of Graduate Alumni Assistant}

Traditional professions dominated the workplace from the 1950s through the 1980s, since they were seen to be secure and predictable at the time. A career is a series of linked occupations that are organized in a hierarchy of status levels, with individuals progressing through the levels in an orderly and predictable manner. The definition of professional success is determined by the organization, and it is often assessed in terms of promotions and increases.

Because career opportunities in flatter companies are restricted, many people are being forced to rethink their perspectives on their professional futures as a result of changes in conventional organizational structures. Because of shifts in career types away from traditional hierarchical jobs and toward jobs that are characterized by a lack of support and organizational constraints, organizations now bear more responsibility for the development of individual knowledge workers rather than the organizations themselves. After knowledge workers have progressed beyond the stage of career entrance, there are four important professional motivators to consider. Personal development, operational autonomy, task completion, and financial gain are the four primary drivers of motivation.

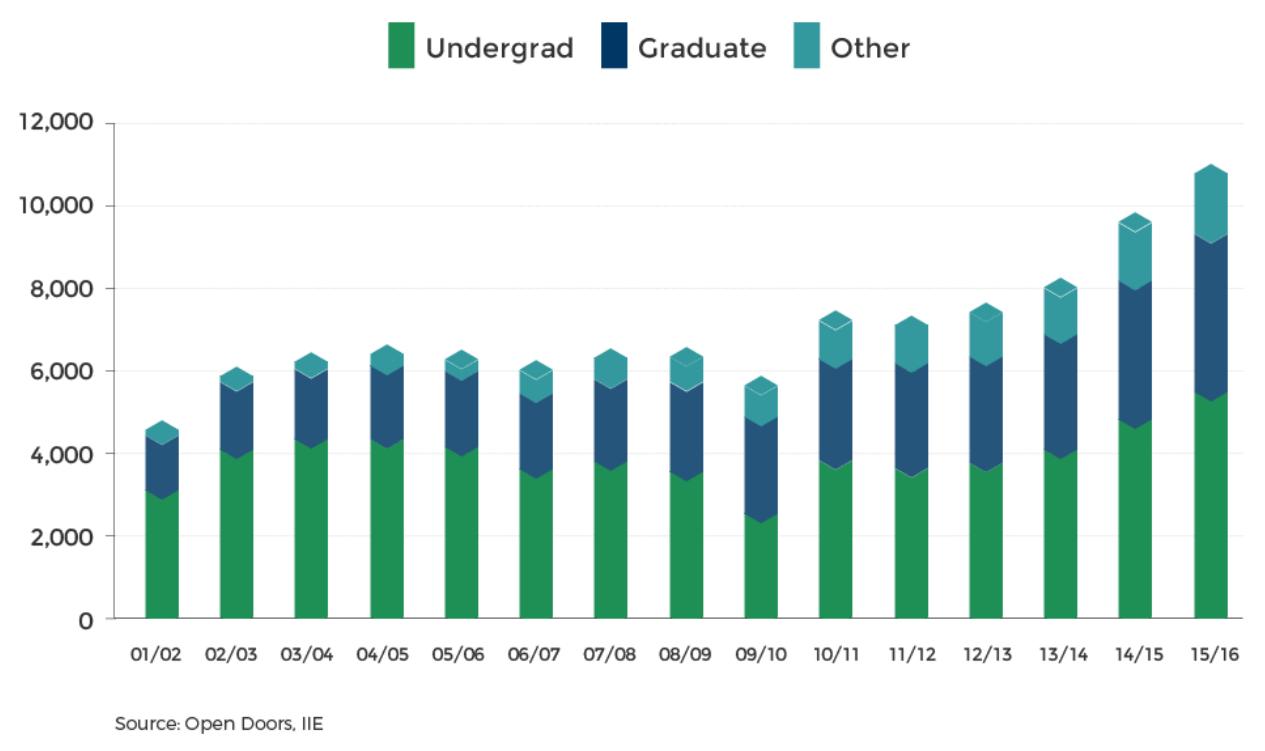

Figure 2. Percentage of Nigerian Students by Academic Level

In terms of motivation, personal growth is the first and most important factor to consider. It may be defined as a chance for people to achieve their full potential via intellectual, personal, and professional development. For knowledge workers to have meaningful and challenging work that will contribute to personal development, organizations must address issues such as 
job design, assignments, and career progression. Employees' personal growth is aided by the acquisition of information, which results in a feeling of achievement and acknowledgment from their peers, as well as the development of their individual and professional selves. Training, mentorship, and the enhancement of the work environment are all important components of career development programs. Compensation packages that are competitive are also important components of career development programs (Chen et al., 2004).

The excitement and difficulties offered by the job done by knowledge workers also aid in the development of the individuals who execute the work. Knowledge workers, such as software developers, want employment that are both demanding and provide learning opportunities. People are motivated when they are drawn to a work, even if the status, perks, or obligations connected with the employment are of little value to them in the long run.

A work environment that enables knowledge workers to have control over the tasks given to them while still operating within the limitations of an organizational context may be characterized as operational autonomy, which is the second most important motivator. The manner in which information is handled is influenced by the organizational culture and the leadership style. It is only through working in dynamic knowledge-based organizations that knowledge workers will be able to define and control their own work, and therefore accept responsibility for their responsibilities. It is necessary for organizational culture to be aligned with the beliefs and habits of knowledge workers in order to offer such a high degree of autonomy. When it comes to attaining this degree of autonomy, the amount of freedom that knowledge worker supervisors offer is critical.

The completion of tasks is the third main motivator, and it may be defined as the feeling of fulfillment that knowledge workers get from creating work of a high level and quality that they can be proud of as a result of their efforts. Affirming the personal objectives of knowledge workers and aligning them with corporate goals will allow them to be driven by task completion to strive towards a shared purpose and be selfless in their actions. Another issue that may arise while completing activities is boredom, which can occur when doing repeated or less difficult jobs. Tasks must stay difficult in order to avoid boredom from eroding the feeling of achievement that knowledge workers get from their professional lives (Petronio \& Colacino, 2008).

Because job security for knowledge workers is dependent on the development of knowledge and skills that can be transferred from one organization to another, the importance of financial compensation (the final motivational factor) may be less important for knowledge workers than for traditional workers. Money is seen as a kind of compensation for the contributions made by knowledge workers to the overall success of the company. When it comes to knowledge workers, money cannot guarantee their retention. Instead, compensation should be structured in accordance with the way work is defined in the organization, and may include a base salary as well as incentive payments, allowances, and pension funds. In the field of career studies, the study of money as a motivating factor is always notable. According to a fascinating discovery in this respect, men knowledge workers change professions more often and earn more money than their female colleagues.

As a result of our country's past, which includes persistent discrimination and inequality, we are obligated to be alert on problems such as values, good citizenship, and a clear commitment to wider development objectives. As a consequence of this, Intentionally, this strategy is included in the broader concept of career development; a concept that describes the obligations that result from the United Nations' broader economic, social, and development agenda. In accordance with the 11 Strategies, the contribution of each person to the South African

Copyright ( 2021, International Journal Papier Public Review, Under the license CC BY-SA 4.0 DOI: https://doi.org/10.47667/ijppr.v2i3.103 
Development Agenda is a function of his or her skills and institutional framework. The productivity of each person is influenced by a variety of factors, including his or her technical abilities, the degree to which his or her fundamental requirements are fulfilled, his or her beliefs and orientation, social inclusion, and dedication to promoting the public interest, among other things. The primary goal of career development is to make a positive contribution to human development (Robertson, 2018; Blustein et al., 2020). In order to respond to the imperatives of economic, social, and broader development, the strategic priorities and interventions that make up the strategy are explicitly designed to do just that.

\section{Understanding How Managerial Career Advancement Happens}

It is critical to understand how workers move from their current roles to management ones. It is necessary to promote (as managers) those who are the most effective, particularly those who come from historically disadvantaged groups. According to research, organizational leaders' poor performance or excellent performance may contribute to the failure or profitability of their organizations (Valdiserri \& Wilson, 2010; Boyne et al., 2011; Meng \& Berger, 2019). Unfortunately, the percentage of competent managers is believed to be less than 50 percent in most countries across the world. The reasons why women and the formerly disadvantaged majority continue to be under-represented in management are equally critical to understanding The path to achieving high-level positions in today's companies is quite different from the one taken two decades ago.

Furthermore, employment level, seniority, and years of service all play an important role in determining career routes to choose. There are fewer management jobs available now, and companies are flatter and more decentralized, with many having been reduced as a result. This necessitates a shift of perspective about how development is being made. Changes have also occurred in human resource management techniques, particularly in the areas of selection and promotion of managers. Selection practices for management positions are now more structured and less subjective than they were a decade ago; equal employment opportunities/affirmative action policies have been implemented; and the pool of applicants for managerial positions is becoming more diverse, with more women, older applicants, and applicants from a wider range of ethnic and racial backgrounds applying for managerial positions than ever before. The definition of managerial career progression is often expressed in terms of promotions within the managerial ranks, the degree of management ultimately attained, and the amount of money earned. Management promotion indicates an upward movement in the managing hierarchy, and a manager's pay level reflects the degree of accomplishment and success in the managerial hierarchy

\section{Conclusion}

The conventional approach to career development is primarily concerned with methods that are intended to use skills development and supply to spur economic growth, rather than with anything else. While the promotion of economic growth is a key aim for career development in South Africa, it is not the sole purpose of the country's development agenda, which includes other objectives as well. A vision of career development that is based on strictly defined economic objectives would be at odds with South Africa's development rhetoric, according to the World Bank.

\section{References}

Blustein, D. L., Erby, W., Meerkins, T., Soldz, I., \& Ezema, G. N. (2020). A critical exploration of assumptions underlying STEM career development. Journal of Career Development, 0894845320974449. 
Boyne, G. A., James, O., John, P., \& Petrovsky, N. (2011). Top management turnover and organizational performance: A test of a contingency model. Public Administration Review, 71(4), 572-581.

Chang, C. L. H., \& Lin, T. C. (2015). The role of organizational culture in the knowledge management process. Journal of Knowledge management.

Chen, T. Y., Chang, P. L., \& Yeh, C. W. (2004). A study of career needs, career development programs, job satisfaction and the turnover intentions of R\&D personnel. Career development international.

Coetzee, M., \& Schreuder, D. (2009). Psychological career resources as predictors of working adults' career anchors: An exploratory study. SA Journal of Industrial Psychology, $35(1), 1-11$.

Di Fabio, A., \& Maree, J. G. (2013). Career counselling: The usefulness of the Career Interest Profile (CIP). Journal of Psychology in Africa, 23(1), 41-49.

Duffy, R. D., \& Dik, B. J. (2009). Beyond the self: External influences in the career development process. The career development quarterly, 58(1), 29-43.

Hong, D., Suh, E., \& Koo, C. (2011). Developing strategies for overcoming barriers to knowledge sharing based on conversational knowledge management: A case study of a financial company. Expert systems with Applications, 38(12), 14417-14427.

Kefela, G. T. (2010). Knowledge-based economy and society has become a vital commodity to countries. International NGO Journal, 5(7), 160-166.

Maruta, R. (2012). Transforming knowledge workers into innovation workers to improve corporate productivity. Knowledge-Based Systems, 30, 35-47.

Meng, J., \& Berger, B. K. (2019). The impact of organizational culture and leadership performance on PR professionals' job satisfaction: Testing the joint mediating effects of engagement and trust. Public Relations Review, 45(1), 64-75.

Petronio, A., \& Colacino, P. (2008). Motivation strategies for knowledge workers: Evidences and challenges. Journal of technology management \& innovation, 3(3), 21-32.

Robertson, P. J. (2018). Positive psychology and career development. British journal of guidance \& counselling, 46(2), 241-254.

Taskforce, A. L. C., Harper, A., Finnerty, P., Martinez, M., Brace, A., Crethar, H. C., ... \& Hammer, T. R. (2013). Association for Lesbian, Gay, Bisexual, and Transgender Issues in Counseling Competencies for counseling with lesbian, gay, bisexual, queer, questioning, intersex, and ally individuals: Approved by the ALGBTIC board on June 22, 2012. Journal of LGBT Issues in Counseling, 7(1), 2-43.

Valdiserri, G. A., \& Wilson, J. L. (2010). The study of leadership in small business organizations: Impact on profitability and organizational success. The Entrepreneurial Executive, 15, 47. 